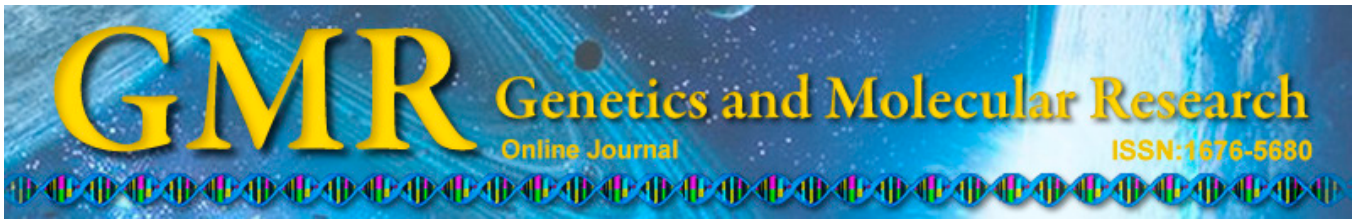

\title{
Genetic polymorphisms in metabolic enzymes and susceptibility to anti-tuberculosis drug-induced hepatic injury
}

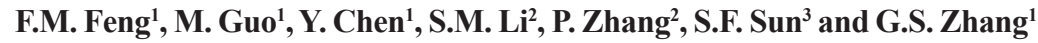 \\ ${ }^{1}$ Key Laboratory of Occupational Health and Safety, School of Public Health, \\ Hebei United University, Tangshan, China \\ ${ }^{2}$ Tanshan Tuberculosis Hospital, Tangshan, China \\ ${ }^{3}$ College of Nursing and Rehabilitation, Hebei United University, \\ Tangshan, China \\ Corresponding author: F.M. Feng \\ E-mail: fm_feng@sina.com
}

Genet. Mol. Res. 13 (4): 9463-9471 (2014)

Received October 16, 2013

Accepted September 18, 2014

Published November 11, 2014

DOI http://dx.doi.org/10.4238/2014.November.11.11

ABSTRACT. We examined the relationships between $N$-transacetylase 2 (NAT2), cytochrome P450 (CYP) 2E1 enzyme, glutathione $S$-transferase M1, T1 (GSTM1/GSTT1) gene polymorphisms, and anti-tuberculosis drug-induced hepatic injury (ADIH). A one-to-one matched case-control study was carried out using clinical data. NAT2, CYP2E1, GSTM1, and GSTT1 polymorphisms were identified in 173 pairs of research subjects. Statistical analysis was performed to determine risk factors of ADIH. The results showed that low body mass index and alcohol consumption were risk factors of $\mathrm{ADIH}$, with odds ratios of 6.852 and 3.203, respectively. The frequencies of NAT2 slow acetylator, CYP2E1 -1259G $>\mathrm{C},-1019 \mathrm{C}>\mathrm{T}$ wild-type, and the GSTM1 null genotype were higher in the case group than in the control group, with odds ratios of 2.260, 2.696, 4.714, and 2.440, respectively. GSTT1 was not found to be related to ADIH. Interactive analysis showed that NAT2 slow acetylator and the GSTM1 null genotype were mutually synergistic, while an antagonistic relationship was observed between 
the CYP2E1 wild-type genotype and the other 3 genetic types. The risks of hepatic injury were higher after anti-tuberculosis therapy in patients carrying the NAT2 slow acetylator, CYP2E1 $-1259 \mathrm{G}>\mathrm{C},-1019 \mathrm{C}>\mathrm{T}$ wild-type, and GSTM1 null genotype.

Key words: Anti-tuberculosis drug-induced hepatic injury; Tuberculosis; Anti-tuberculosis therapy; Gene polymorphism; Metabolic enzyme

\section{INTRODUCTION}

Tuberculosis resulting from infection of Mycobacterium tuberculosis affects onethird of the world population. In 2010, more than 8.8 million people were diagnosed with tuberculosis (World Health Organization, 2011). Standard first-line anti-tuberculosis (anti-TB) chemotherapy regimens recommended by the WHO include isoniazid (INH), rifampicin, and pyrazinamide (World Health Organization, 2009), with an effective rate of 97\%; however, these drugs show hepatotoxicity (Forget and Menzies, 2006). The hepatotoxicity of pyrazinamide was found to be higher than that of INH and rifampicin (Yee et al., 2003), with the negative effects amplified when the drugs are used together (Steele et al., 1991). Previous studies found that combination therapy of chemotherapy and anti-TB drugs increased hepatic injury by $2-28 \%$ (Durand et al., 1996; Tostmann et al., 2008); however, this rate varied widely by region. In extreme cases, patients may be forced to alter the chemotherapy regimen or even stop chemotherapy. Therefore, anti-tuberculosis drug-induced hepatic injury (ADIH) has prevented effective anti-TB therapy in some cases.

Hepatic injury occurs when toxic metabolites of drugs in the liver cannot be eliminated. In addition to environmental factors (Singla et al., 2010), drug metabolic enzymes play an important role in processes such as oxidation, deoxidation, hydrolysis of the phase I metabolic enzyme cytochrome P450 2E1 (CYP2E1), and catalysis conjugation reactions of the phase II metabolic enzymes $N$-acetyltransferase (NAT2), glutathione $S$-transferase M1 (GSTM1), and glutathione $S$-transferase T1 (GSTT1). NAT2 is classified into two groups depending on rapid acetylation and slow acetylation; wild-type NAT2 is a fast acetylator (Fretland et al., 2001), while two mutant alleles in the enzyme DNA sequence cause it to be a slow acetylator (Bell et al., 1993; Hein et al., 2000). Genetic polymorphisms influence INH metabolism (Sunahara et al., 1961). Studies in Taiwan, Japan, and Korea found that individuals carrying the NAT2 slow acetylator variant had a higher risk of ADIH than those carrying the rapid acetylator form (Huang et al., 2002; Hiratsuka et al., 2002; Cho et al., 2007). CYP2E1 enzyme is a cytochrome $\mathrm{P} 450$ super-gene family member and contains at least 8 polymorphic loci. Among them, $-1259 \mathrm{G}>\mathrm{C}$ and $-1019 \mathrm{C}>\mathrm{T}$ are located in the 5 '-end of the gene, and are closely related to CYP2E1 expression. Various studies have demonstrated that individuals carrying wild-type CYP2E1 genes have a higher risk of developing ADIH (Huang et al., 2003), but a study in Korea found no relationship between CYP2E1 genetic polymorphisms and ADIH (Vuilleumier et al., 2006). GSTM1 and GSTT1 are common polymorphisms; when there is a deletion mutation in homozygous genes, the corresponding enzyme loses activity, which further increases hepatotoxicity induced by anti-TB drugs (Bruhn et al., 1998).

A meta-analysis confirmed that polymorphisms in CYP2E1, NAT2, and GSTM1 were related to ADIH (Sun et al., 2008), whereas the effects of different drug metabolic enzymes were mixed during ADIH (Fukino et al., 2008), as they showed either synergism or antago- 
nism. In this study, we used a one-to-one matched case-control method to explore the relationships between metabolic enzyme gene polymorphisms of the 3 drugs and ADIH by examining the toxicity of drug metabolites and their detoxification process, as well as their interactions.

\section{MATERIAL AND METHODS}

\section{Subjects}

The research subjects were pulmonary tuberculosis patients of Han ethnicity diagnosed as eligible to participate in the study by Tangshan Tuberculosis Hospital between August 2010 and December 2011. A total of 173 pairs of subjects were included in this one-toone matched case-control study. The study was approved by the Ethics Committee of Hebei United University (Document code: 10-007) and written informed consent was obtained from all enrolled patients.

\section{Selection of cases}

The cases were selected based on liver functions, i.e., all indices of liver function were normal before anti-TB chemotherapy, and became abnormal indicating hepatic injury after 6 months of chemotherapy. "Hepatic injury" was defined according to the American Thoracic Society criteria (Saukkonen et al., 2006), excluding those with abnormal liver function before chemotherapy. For drug-induced liver disorders, cases were patients who showed anti-TB druginduced hepatitis based on increased serum transaminase values that were 3 -fold higher than the normal upper limit (40 IU/L alanine aminotransferase) and symptoms compatible with hepatitis.

\section{Selection of controls}

In this one-to-one matched case-control study, the controls underwent the same antiTB chemotherapy with the selected cases and were not tested with abnormality in liver functions after 6 months of the chemotherapy. The controls selected matched the criteria compared to the cases: i) same gender; ii) age discrepancy of less than 5 years; iii) living in the same regions; and iv) treatment with anti-TB drug regimens at the usual dosage, including $300 \mathrm{mg} /$ day INH, $450 \mathrm{mg}$ /day rifampicin, and $1500 \mathrm{mg}$ /day pyrazinamide. Other disposal and exclusion criteria for the control group were the same as those used in the cases.

\section{Epidemiological survey}

A face-to-face interview was conducted to determine the subjects' marital status, occupations, body mass index, degree of addiction to alcohol and tobacco, medical history, prior/ concomitant medications, anti-TB chemotherapy regimen, and results of liver function tests before and after medications. Conditional logistic regression was applied to measure the associations between subjects' characteristics and ADIH.

\section{Genotype identification}

Three milliliters of peripheral venous blood was drawn from fasted subjects for liver 
function tests. Another $2 \mathrm{~mL}$ blood containing ethylenediaminetetraacetic acid for anticoagulation was stored at $-70^{\circ} \mathrm{C}$. Genomic DNA was extracted from $500 \mu \mathrm{L}$ frozen whole blood by column chromatography. Polymorphisms at the $481 \mathrm{C}>\mathrm{T}, 590 \mathrm{G}>\mathrm{A}$, and $857 \mathrm{G}>\mathrm{A}$ loci of the NAT2 gene, $-1259 \mathrm{G}>\mathrm{C}$ and $-1019 \mathrm{C}>\mathrm{T}$ loci of the CYP2E1 gene, and the genes GSTM1 and GSTT1 for all subjects were analyzed by Tian Gen Biotechnology (Beijing, China) using DNA sequencing.

The mutated alleles from the loci $481 \mathrm{C}>\mathrm{T}, 590 \mathrm{G}>\mathrm{A}$, and $857 \mathrm{G}>\mathrm{A}$ of the NAT2 gene are represented as M1, M2, and M3, and the wild-types are represented as WT. The 4 alleles of NAT2 constituted 10 genotypes, including WT/WT, WT/M1, WT/M2, WT/M3, M1/M1, M1/M2, M1/M3, M2/M2, M2/M3, and M3/M3. Based on Bell et al. (1993), the subjects were classified as rapid and slow acetylators, with individuals containing 2 mutant alleles defined as slow acetylators and those containing at least $1 \mathrm{WT}$ allele defined as rapid acetylators.

\section{Statistical analysis}

Conditional logistic regressions were conducted for univariate or multivariate analyses using SPSS 14.5 (SPSS, Inc., Chicago, IL, USA). Dichotomy analysis was applied to observe the interactions between gene locus polymorphism of the drug metabolic enzyme. Bonferroni's correction was used for two-sided tests with an inspection level of $\alpha=0.025$.

\section{RESULTS}

\section{Basic characteristics of the subjects}

Among the 173 pairs of cases and controls, 118 pairs were males and 55 pairs were females. The average age was $48.8 \pm 19.2$ years (range, $15-88$ years) in the case group and $48.6 \pm$ 19.3 years (range, $17-85$ years) in the control group. A total of 110 pairs were from rural areas and 63 were from urban areas. Hepatic injuries after anti-TB chemotherapy within the first, second, and third months were observed in 113, 41, and 19 patients, respectively, indicating that $89 \%$ of hepatic injuries occurred in the first 2 months of chemotherapy. No hepatic injury was found after 3 months of chemotherapy.

\section{Factors associated with ADIH}

The results showed that marital status, degree of education, occupation, and tuberculosis type did not significantly differ between the 2 groups, whereas body mass index and drinking status significantly differed in the single-factor analyses (Table 1).

\section{Gene polymorphisms and ADIH}

\section{Single-factor and multiple-factor analyses of ADIH and gene polymorphisms}

Analysis of Hardy-Weinberg equilibrium showed that the goodness of fits of genes NAT2, GST, and CYP2E1 were excellent, with P values higher than 0.10 , demonstrating that the control populations were in equilibrium and that the sample populations were representative of the larger population.

Single-factor logistic regression analysis indicated that the risks of hepatic injury af- 
ter anti-TB chemotherapy for individuals carrying the slow acetylator variant were 2.26 -fold higher than in individuals carrying the rapid acetylator form. The $-1259 \mathrm{G}>\mathrm{C}$ and $-1019 \mathrm{C}>\mathrm{T}$ wild type of the CYP2E1 gene and the GSTM1 null genotype were related to ADIH, although the null genotype difference of GSTT1 in the 2 groups was not statistically significant (Table 2).

Table 1. Single-factor logistic regression analysis of anti-tuberculosis drug-induced hepatic injury-influencing
factors.
\begin{tabular}{lcccccc}
\hline Factors & $\beta$ & SE & Wald $\chi^{2}$ & P & OR & $95 \%$ CI \\
\hline Marital status & 0.456 & 0.377 & 1.461 & 0.227 & 0.634 & $0.302-1.328$ \\
Degree of education & -0.489 & 0.255 & 3.675 & 0.055 & 0.614 & $0.372-1.011$ \\
Occupation & 0.233 & 0.198 & 1.394 & 0.238 & 1.263 & $0.857-1.860$ \\
Body mass index & 1.925 & 0.531 & 13.118 & 0.001 & 6.852 & $2.418-19.413$ \\
Smoking status & 0.271 & 0.331 & 0.671 & 0.413 & 1.311 & $0.6865-2.508$ \\
Drinking status & 1.164 & 0.397 & 8.576 & 0.003 & 3.203 & $1.470-6.980$ \\
\hline
\end{tabular}

Table 2. Genotype of NAT2, CYP2E1, and GST associated with anti-tuberculosis drug-induced hepatic injury.

\begin{tabular}{|c|c|c|c|c|c|c|}
\hline \multirow[t]{2}{*}{ Controls } & \multicolumn{2}{|c|}{ Cases } & \multirow[t]{2}{*}{ Wald $\chi^{2}$} & \multirow[t]{2}{*}{$\mathrm{P}$} & \multirow[t]{2}{*}{ OR } & \multirow[t]{2}{*}{$95 \% \mathrm{CI}$} \\
\hline & Slow acetylator of $N A T 2$ & Rapid acetylator of $N A T 2$ & & & & \\
\hline Slow acetylator of $N A T 2$ & 13 & 19 & 7.999 & 0.005 & 2.260 & $1.265-3.654$ \\
\hline Rapid acetylator of $N A T 2$ & 43 & $\begin{array}{c}98 \\
\end{array}$ & & & & \\
\hline & CYP $2 E 1-1259 \mathrm{G}>\mathrm{G}$ & $C Y P 2 E 1-1259 \mathrm{C}>\mathrm{C}+\mathrm{G}>\mathrm{C}$ & & & & \\
\hline CYP $2 E 1-1259 \mathrm{G}>\mathrm{G}$ & 74 & 23 & 16.497 & 0.000 & 2.696 & $1.670-4.350$ \\
\hline$C Y P 2 E 1-1259 \mathrm{C}>\mathrm{C}+\mathrm{G}>\mathrm{C}$ & $\begin{array}{c}62 \\
C Y P 2 E 1-1019 \mathrm{C}>\mathrm{C}\end{array}$ & $\begin{array}{c}14 \\
C Y P 2 E 1-1019 \mathrm{~T}>\mathrm{T}+\mathrm{C}>\mathrm{T}\end{array}$ & & & & \\
\hline CYP $2 E 1-1019 \mathrm{C}>\mathrm{C}$ & 76 & 14 & 27.770 & 0.000 & 4.714 & $2.648-8.392$ \\
\hline$C Y P 2 E 1-1019 \mathrm{~T}>\mathrm{T}+\mathrm{C}>\mathrm{T}$ & $\begin{array}{c}66 \\
\text { GSTM1 null }\end{array}$ & $\begin{array}{c}17 \\
\text { GSTMI WT }\end{array}$ & & & & \\
\hline GSTM1 null & 15 & 24 & 14.109 & 0.001 & 2.440 & $1.532-3.886$ \\
\hline GSTMI WT & 64 & 70 & & & & \\
\hline & GSTT1 null & GSTT1 WT & & & & \\
\hline GSTT1 null & 31 & 40 & 1.323 & 0.250 & 1.275 & $0.843-1.929$ \\
\hline GSTTI WT & 51 & 51 & & & & \\
\hline
\end{tabular}

To prevent interference among studied factors and to control for potential confounding factors, multiple-factor analysis was carried out using significant factors in the single-factor analysis as covariates (Table 3). Multiple-factor logistic regression analysis showed that after adjusting for body mass index and alcohol consumption, the NAT2 slow acetylator, CYP2E1 $-1259 \mathrm{G}>\mathrm{C}$ and $-1019 \mathrm{C}>\mathrm{T}$ wild type, and GSTM1 null type were still significantly correlated with ADIH, with odds ratios (ORs) and 95\% confidence intervals (95\%CIs) of 2.146 (1.2123.801), 2.541 (1.529-4.221), 5.115 (2.728-9.953), and 2.686 (1.607-4.491), respectively.

\section{Interactive analysis of gene locus polymorphism}

Based on the genotype characteristics of the subjects, dichotomy analysis was performed to explore the relationships between interactions of different genotypes of various metabolic enzymes and ADIH. The results showed that in phase II metabolic enzyme genes, synergism existed between the GSTM1 null genotype, NAT2 slow acetylator, and GSTT1 null 
genotype, with interaction coefficients of $6.021,3.894$, and 1.316, respectively. A super-multiplication effect was observed between the GSTM1 null genotype and NAT2 slow acetylator, and a secondary multiplication between GSTT1 null genotype with GSTM1 null genotype and $N A T 2$ slow acetylator. There was also an interaction between the phase I metabolic enzyme and phase II metabolic enzyme genes NAT2, GSTM1, and GSTT1. Among subjects carrying the CYP2E1 mutant genotype and NAT2 slow acetylator phenotype, the $\mathrm{ORg}_{1}$ of ADIH was 6.382, while for subjects carrying the CYP2E1 WT genotype and NAT2 slow acetylator type, the $\mathrm{ORg}_{1} \mathrm{~g}_{2}$ of $N A T 2$ decreased to 3.619 , indicating that the CYP2E1 genotype had receding effects on the NAT2 slow acetylator $(r=0.705)$. In addition, antagonism existed between the CYP2E1 WT genotype and GSTM1 null genotype $(\mathrm{OR}=6.625,95 \% \mathrm{CI}=2.517-15.437)$ and GSTT1 null genotype $(\mathrm{OR}=2.480,95 \% \mathrm{CI}=1.314-5.017)$. The interactions between these genes were all secondary multiplication effects.

Table 3. Multiple-factor logistic regression analysis associated with anti-tuberculosis drug-induced hepatic injury.

\begin{tabular}{|c|c|c|c|c|c|c|c|}
\hline Model & Variable names & $\hat{\beta}$ & SE & Wald $\chi^{2}$ & $\mathrm{P}$ & OR & $95 \% \mathrm{CI}$ \\
\hline \multirow[t]{4}{*}{ NAT2 acetylator } & Rapid acetylator & & & & & 1.000 (ref.) & \\
\hline & Slow acetylator & 0.764 & 0.292 & 6.857 & 0.009 & 2.146 & $1.212-3.801$ \\
\hline & Body mass index & 1.912 & 0.539 & 12.597 & 0.000 & 6.670 & $2.355-19.644$ \\
\hline & Drinking status & 1.353 & 0.377 & 12.904 & 0.000 & 3.867 & $1.849-8.089$ \\
\hline \multirow[t]{4}{*}{ CYP $2 E 1-1259 \mathrm{G}>\mathrm{C}$} & $\mathrm{G}>\mathrm{G}$ & & & & & 1.000 (ref.) & \\
\hline & $\mathrm{G}>\mathrm{C}+\mathrm{C}>\mathrm{C}$ & 0.932 & 0.259 & 12.962 & 0.000 & 2.541 & $1.529-4.221$ \\
\hline & Body mass index & 1.879 & 0.515 & 13.317 & 0.000 & 6.545 & $2.386-17.954$ \\
\hline & Drinking status & 1.210 & 0.393 & 9.457 & 0.002 & 3.353 & $1.551-7.249$ \\
\hline \multirow[t]{4}{*}{ CYP2E1-1019C $>\mathrm{T}$} & $\mathrm{C}>\mathrm{C}$ & & & & & 1.000 (ref.) & \\
\hline & $\mathrm{C}>\mathrm{T}+\mathrm{T}>\mathrm{T}$ & 1.632 & 0.321 & 25.882 & 0.000 & 5.115 & $2.728-9.953$ \\
\hline & Body mass index & 2.099 & 0.536 & 15.306 & 0.000 & 8.154 & $2.850-23.331$ \\
\hline & Drinking status & 1.245 & 0.423 & 8.687 & 0.003 & 3.474 & $1.518-7.954$ \\
\hline \multirow[t]{4}{*}{ GSTM1 } & GSTMI wild & & & & & 1.000 (ref.) & \\
\hline & GSTMI null & 0.988 & 0.262 & 14.197 & 0.000 & 2.686 & $1.607-4.491$ \\
\hline & Body mass index & 2.007 & 0.526 & 14.584 & 0.000 & 7.440 & $2.656-20.840$ \\
\hline & Drinking status & 1.381 & 0.396 & 12.166 & 0.000 & 3.977 & $1.831-8.639$ \\
\hline \multirow[t]{4}{*}{ GSTT1 } & GSTT1 wild & & & & & 1.000 (ref.) & \\
\hline & GSTTI null & 0.165 & 0.232 & 0.510 & 0.475 & 1.180 & $0.749-1.858$ \\
\hline & Body mass index & 1.912 & 0.518 & 13.622 & 0.000 & 6.768 & $2.452-18.685$ \\
\hline & Drinking status & 1.291 & 0.379 & 11.638 & 0.001 & 3.637 & $1.732-7.638$ \\
\hline
\end{tabular}

\section{DISCUSSION}

Patients commonly respond to the same anti-TB chemotherapy regimen differently, both in terms of efficacy and side effects. Thus, physicians may face challenges in choosing an appropriate chemotherapy regimen for individual patients.

The frequently used first-line anti-TB drugs show varying degrees of hepatotoxicity. Hepatic injury occurs when toxic metabolites of these drugs in the liver cannot be made less toxic. However, patients with hepatic injury may also have other diseases causing abnormal liver function, such as viral hepatitis, alcoholic liver disease, autoimmunity hepatitis, hypoxia, bacteremia, and congestive heart-failure. In addition, drugs such as antibiotic chloramphenicol, analgesic-antipyretic, paracetamol, and the antipsychotic drug chlopromazine may cause abnormal liver functions.

This one-to-one matched case-control study excluded influences caused by relevant factors such as age and gender. In addition, we used a matching design for the chemotherapy 
programs, whose efficiencies of both research design and statistical tests were higher than similar studies in the past.

As one of the important members of the P450 family, CYP2E1 participates in the metabolism of various drugs. Under the inhibitory action of INH, the enzymatic activity of WT CTP2E1 is higher than that of the mutant type and produces more metabolism with higher hepatotoxicity, increasing the risk of drug-induced hepatic injury. Therefore, phase I metabolic enzymes of CYP2E1 contribute to liver toxicity. CYP2E1 activities are normally distributed in the general population; however, nonconformity has been observed in both domestic and overseas studies, due to apparent racial differences. Studies have shown that the WT genotype of tuberculosis patients of Han nationality in the case group was higher than that in the control group, which agrees with the results of Vuilleumier et al. (2006), Lee et al. (2010), and Wang et al. (2010). A study conducted by Huang et al. (2003) showed that risks of hepatic injury in individuals carrying the WT genotype were 2.38-fold higher than in those carrying mutant genes, while studies in Korea and Brazil showed no evidence of significant differences between patients with the WT and mutant gene (Cho et al., 2007; Teixeira et al., 2011).

NAT2 is a phase II metabolic enzyme; however, the role of NAT2 polymorphisms in $\mathrm{ADIH}$ is not consistent, as genotype distributions vary by region and race, and studies in the field hold different standards for hepatic injury. The risk of hepatic injury in individuals carrying NAT2 slow acetylators was 2.26-fold higher than in those carrying rapid acetylators. These results are consistent with those of studies conducted in Taiwan (Huang et al., 2002; Lee et al., 2010), Tunisia (Ben et al., 2012), Brazil (Teixeira et al., 2011), and Iran (Khalili et al., 2011), but differ from those of studies conducted in the USA, which showed the opposite conclusion that the hepatotoxicity of rapid acetylators was higher than that of slow acetylators (Mitchell et al., 1975); this suggests that discrepancies may be due to differences in race.

GST is a superfamily of drug-metabolic enzymes, and includes various types of isoenzymes. The main functions of these enzymes are to catalyze and deoxidate glutathione and chemical structure-versatile electrophilic compounds by converting polar eletrophilic compounds into nonpolar hydrophilic compounds for elimination from the body, thus playing a role in detoxification. The frequencies of GSTM1 and GSTT1 null genotypes among different races and in different regions fluctuate between 21 and 100\% and between 11 and 64.4\%, respectively (Nelson et al., 1995). In this study, the frequency of the GSTM1 null genotype in the case group was 2.44-fold higher than that in the control group, and no statistical difference was found in the distribution of GSTT1 gene locus polymorphisms between the 2 groups. The results are consistent with those of Roy et al. (2001) in an Indian population.

A synergetic interaction was observed between the phase II metabolic enzyme GSTM1 null genotype, NAT2 slow acetylator, and GSTT1 null genotype according to interactive analysis. The GSTM1 null genotype modifies the hepatic injury effect of the NAT2 slow acetylator and GSTT1 null genotype, as well as amplifies the effect of the GSTT1 null genotype to a NAT2 slow acetylator; however, an antagonistic relationship was observed between the phase I metabolic enzyme gene CYP2E1 and the phase II metabolic enzyme genes NAT2, GSTM1, and GSTT1, indicating that the CYP2E1 WT genotype weakens the effect of NAT2 slow acetylator. Thus, genotyping improves the understanding of drug enzyme metabolic capacity, providing guidance for physicians in selecting less hepatic toxic anti-TB drugs. 


\section{ACKNOWLEDGMENTS}

We are grateful to the staffs of Tanshan Tuberculosis Hospital, whose hard work made this study possible. Special thanks to the pulmonary tuberculosis patients who participated in this study. Research supported by the National Natural Science Foundation of China (\#81041096) and the Science Foundation of the Key Laboratory of Tangshan (\#08150201A-1-8).

\section{REFERENCES}

Bell DA, Taylor JA, Butler MA, Stephens EA, et al. (1993). Genotype/phenotype discordance for human arylamine $\mathrm{N}$-acetyltransferase (NAT2) reveals a new slow-acetylator allele common in African-Americans. Carcinogenesis 14: $1689-1692$

Ben ML, Ghozzi H, Kamoun A, Hakim A, et al. (2012). Polymorphism of the N-acetyltransferase 2 gene as a susceptibility risk factor for antituberculosis drug-induced hepatotoxicity in Tunisian patients with tuberculosis. Pathol. Biol. 60: 324-330.

Bruhn C, Brockmoller J, Kerb R, Roots I, et al. (1998). Concordance between enzyme activity and genotype of glutathione S-transferase theta (GSTT1). Biochem. Pharmacol. 56: 1189-1193.

Cho HJ, Koh WJ, Ryu YJ, Ki CS, et al. (2007). Genetic polymorphisms of NAT2 and CYP2E1 associated with antituberculosis drug-induced hepatotoxicity in Korean patients with pulmonary tuberculosis. Tuberculosis 87: 551-556.

Durand F, Jebrak G, Pessayre D, Fournier M, et al. (1996). Hepatotoxicity of antitubercular treatments. Rationale for monitoring liver status. Drug Saf. 15: 394-405.

Forget EJ and Menzies D (2006). Adverse reactions to first-line antituberculosis drugs. Expert Opin. Drug Saf. 5: 231-249.

Fretland AJ, Leff MA, Doll MA and Hein DW (2001). Functional characterization of human N-acetyltransferase 2 (NAT2) single nucleotide polymorphisms. Pharmacogenetics 11: 207-215.

Fukino K, Sasaki Y, Hirai S, Nakamura T, et al. (2008). Effects of N-acetyltransferase 2 (NAT2), CYP2E1 and glutathioneS-transferase (GST) genotypes on the serum concentrations of isoniazid and metabolites in tuberculosis patients. $J$. Toxicol. Sci. 33: 187-195.

Hein DW, Doll MA, Fretland AJ, Leff MA, et al. (2000). Molecular genetics and epidemiology of the NAT1 and NAT2 acetylation polymorphisms. Cancer Epidemiol. Biomarkers Prev. 9: 29-42.

Hiratsuka M, Kishikawa Y, Takekuma Y, Matsuura M, et al. (2002). Genotyping of the N-acetyltransferase2 polymorphism in the prediction of adverse drug reactions to isoniazid in Japanese patients. Drug Metab. Pharmacokinet. 17: 357-362.

Huang YS, Chern HD, Su WJ, Wu JC, et al. (2002). Polymorphism of the $\mathrm{N}$-acetyltransferase 2 gene as a susceptibility risk factor for antituberculosis drug-induced hepatitis. Hepatology 35: 883-889.

Huang YS, Chern HD, Su WJ, Wu JC, et al. (2003). Cytochrome P450 2E1 genotype and the susceptibility to antituberculosis drug-induced hepatitis. Hepatology 37: 924-930.

Khalili H, Fouladdel S, Sistanizad M, Hajiabdolbaghi M, et al. (2011). Association of N-acetyltransferase-2 genotypes and anti-tuberculosis induced liver injury; first case-controlled study from Iran. Curr. Drug Saf. 6: 17-22.

Lee SW, Chung LS, Huang HH, Chuang TY, et al. (2010). NAT2 and CYP2E1 polymorphisms and susceptibility to firstline anti-tuberculosis drug-induced hepatitis. Int. J. Tuberc. Lung Dis. 14: 622-626.

Mitchell JR, Thorgeirsson UP, Black M, Timbrell JA, et al. (1975). Increased incidence of isoniazid hepatitis in rapid acetylators: possible relation to hydranize metabolites. Clin. Pharmacol. Ther. 18: 70-79.

Nelson HH, Wiencke JK, Christiani DC, Cheng TJ, et al. (1995). Ethnic differences in the prevalence of the homozygous deleted genotype of glutathione S-transferase theta. Carcinogenesis 16: 1243-1245.

Roy B, Chowdhury A, Kundu S, Santra A, et al. (2001). Increased risk of antituberculosis drug-induced hepatotoxicity in individuals with glutathione S-transferase M1 'null' mutation. J. Gastroenterol. Hepatol. 16: 1033-1037.

Saukkonen JJ, Cohn DL, Jasmer RM, Schenker S, et al. (2006). An official ATS statement: hepatotoxicity of antituberculosis therapy. Am. J. Respir. Crit. Care Med. 174: 935-952.

Singla R, Sharma SK, Mohan A, Makharia G, et al. (2010). Evaluation of risk factors for antituberculosis treatment induced hepatotoxicity. Indian J. Med. Res. 132: 81-86.

Steele MA, Burk RF and DesPrez RM (1991). Toxic hepatitis with isoniazid and rifampin. A meta-analysis. Chest 99: 465-471.

Sun F, Chen Y, Xiang Y and Zhan S (2008). Drug-metabolising enzyme polymorphisms and predisposition to antituberculosis drug-induced liver injury: a meta-analysis. Int. J. Tuberc. Lung Dis. 12: 994-1002. 
Sunahara S, Uranon and Ogawan (1961). Genetical and geographic studies on isoniazid inactivation. Science 134: 1530-1531. Teixeira RL, Morato RG, Cabello PH, Muniz LM, et al. (2011). Genetic polymorphisms of NAT2, CYP2E1 and GST enzymes and the occurrence of antituberculosis drug-induced hepatitis in Brazilian TB patients. Mem. Inst. Oswaldo Cruz 106: 716-724.

Tostmann A, Boeree MJ, Aarnoutse RE, de Lange WC, et al. (2008). Antituberculosis drug-induced hepatotoxicity: concise up-to-date review. J. Gastroenterol. Hepatol. 23: 192-202.

Vuilleumier N, Rossier MF, Chiappe A, Degoumois F, et al. (2006). CYP2E1 genotype and isoniazid-induced hepatotoxicity in patients treated for latent tuberculosis. Eur. J. Clin. Pharmacol. 62: 423-429.

Wang T, Yu HT, Wang W, Pan YY, et al. (2010). Genetic polymorphisms of cytochrome P450 and glutathione S-transferase associated with antituberculosis drug-induced hepatotoxicity in Chinese tuberculosis patients. J. Int. Med. Res. 38: 977-986.

World Health Organization (WHO) (2009). Treatment of Tuberculosis. Guidelines. 4th edn. WHO / HTM / TB / 2009. 420; 2009. 29, Geneva.

World Health Organization (WHO) (2011). Global Tuberculosis Control. WHO report 2011: WHO / HTM / TB / 2011. 16; 2011. 1, Geneva.

Yee D, Valiquette C, Pelletier M, Parisien I, et al. (2003). Incidence of serious side effects from first-line antituberculosis drugs among patients treated for active tuberculosis. Am. J. Respir. Crit. Care Med. 167: 1472-1477. 